\title{
Formação de professores de Ciências Biológicas e a preocupação com as necessidades específicas na sala de aula
}

\author{
Simone Medianeira Franzin* \\ Andrielli da Silva Fontoura** \\ Gabriela Lanes de Almeida*** \\ Valquiria Simon ${ }^{* * *}$
}

\section{Resumo}

O trabalho aqui desenvolvido se refere ao estudo realizado nas APAEs de São Vicente do Sul e Jaguari, no estado do Rio Grande do Sul, pelos alunos do Grupo PETBiologia. As APAEs, como centros de recebimento de alunos com algum tipo de necessidade, exercem papel fundamental no apoio e inclusão dos alunos na sociedade. O trabalho teve como objetivo reconhecer a realidade das pessoas com necessidades específicas, em específico nas APAEs de São Vicente do Sul e Jaguari/ RS , bem como ampliar os conhecimentos dos futuros profissionais do curso de licenciatura em Ciências Biológicas nessa área, também avaliar a situação de atendimentos das APAEs, interagir com alunos e profissionais, a fim de promover uma integração com o grupo PET- Biologia, conhecer a realidade das famílias dos alunos, e contribuir para a melhoria da qualidade de vida dos mesmos. O trabalho foi desenvolvido pelas acadêmicas do Instituto Federal Farroupilha - Campus São Vicente do Sul, na forma de entrevista, realizada aos funcionários e pais de alunos das APAEs. Como resultados, observaram-se a necessidade de maiores investimentos e realização de atividade de apoio como neurologia. Assim, os alunos do Grupo PET-Biologia poderão contribuir para o apoio e a inclusão de pessoas com necessidades específicas, estando preparados a valorizar a diversidade como aspecto importante no processo de ensino-aprendizagem.

Palavras-chave: Atendimentos nas APAEs; Educação inclusiva; Interação dos licenciandos.

\footnotetext{
* Professora Doutora do Instituto Federal Farroupilha de São Vicente do Sul. São Vicente do Sul, Rio Grade do Sul, Brasil.

** Acadêmica do Curso de Licenciatura em Ciências Biológicas do Instituto Federal Farroupilha de São Vicente do Sul. São Vicente do Sul, Rio Grade do Sul, Brasil.

*** Acadêmica do Curso de Licenciatura em Ciências Biológicas do Instituto Federal Farroupilha de São Vicente do Sul. São Vicente do Sul, Rio Grade do Sul, Brasil.

**** Acadêmica do Curso de Licenciatura em Ciências Biológicas do Instituto Federal Farroupilha de São Vicente do Sul. São Vicente do Sul, Rio Grade do Sul, Brasil.
} 


\section{Teacher training in Biological Sciences and the worry about special needs in the classroom}

\section{Abstract}

The work developed here is related to the study carried out in São Vicente do Sul and Jaguari's APAEs by the students of the PET-Biology Group. The APAEs are centers that receive students with special needs, they play a basic role in the support and inclusion of the pupils in society. The study aimed to assess the situation Care of APAEs, promote interaction of undergraduates in Biological Sciences with APAEs' students and know the reality of students' families, contribute to improving the quality of life for themselves and verify the interest in performing activities with PET-Biology group. The work was developed in the Instituto Federal Farroupilha - Campus SVS through interviews with employees and parents of APAEs' students. As a result, it was observed the necessity of greater amounts of investments and accomplishment of support activities as neurology. Thus, the students of the PET-Biology Group will be able to contribute to the inclusion of special people with necessities, getting more prepared to their teaching professional performance.

Keywords: Special needs; Inclusive education; Teachers' education.

\section{Introdução}

Programas que possibilitem açôes de aprendizado aos professores são fundamentais para promoverem a inclusão de pessoas com necessidades específicas nas salas de aula, garantindo um ensino de qualidade e igualdade de direitos. Assim, a formação de professores precisa ser repensada sob esse aspecto.

O professor deve valorizar a diversidade como aspecto importante no processo de ensino-aprendizagem. Além disso, necessita ser capaz de construir estratégias de ensino, bem como adaptar atividades e conteúdos, não só em relação aos alunos considerados especiais, mas para a prática educativa como um todo, diminuindo, assim, a segregação, a evasão e o fracasso escolar. (PLETSH, 2009, p. 149).

Nesse sentido, o Programa de Educação Tutorial PET-Biologia do Curso de Licenciatura em Ciências Biológicas vem integrando ensino, pesquisa e extensão, por meio de atividades extracurriculares que complementam sua formação acadêmica dentro do curso de formação de professores de Ciências Biológicas. A atuação desse grupo tem como um dos objetivos conhecer a realidade das pessoas com necessidades específicas, a partir da interação com as APAEs, possibilitando experiências para a futura ação profissional.

A educação inclusiva, no Brasil, tem ganhado ênfase nos últimos anos e busca atender aos alunos com necessidades educativas especiais, promovendo a aprendizagem e o conhecimento de todos em um mesmo ambiente de ensino-aprendizagem. 
Considera-se um desafio, nos dias de hoje, a necessidade de incluir pessoas com necessidades específicas na sociedade (TORRES, 2010). Dessa forma, se prevê a garantia dos seus direitos de cidadão, que frequenta a escola e carece ter as mesmas oportunidades de igualdade. Essa preocupação não é infundada, visto que os dados de pesquisa indicam que $15 \%$ da população brasileira apresentam algum tipo de necessidades específicas.

O Censo realizado no ano de 2000 pelo Instituto Brasileiro de Geografia e Estatística (IBGE), mostrou que o país tem cerca de 25 milhóes de pessoas com deficiências físicas, sensoriais ou intelectuais. Dessas, mais da metade tem apenas três anos ou menos de estudo. (TORRES, 2010, p. 4).

No fim do ano de 2009, a resolução n. 4/09 do Conselho Nacional de Educação (CNE) estabeleceu que os alunos com deficiências, transtornos globais do desenvolvimento e superdotaçáo devem ser matriculados nas classes comuns do ensino regular. A Lei de Diretrizes e Bases da Educação Nacional (LDBN) e a Constituição Federal preveem que esses alunos sejam preferencialmente matriculados na rede regular de ensino, mas deixando aberta a possibilidade da opçáo pelas escolas ou classes especiais. Assim, uma alternativa é o atendimento educacional especializado a esses estudantes, realizado, prioritariamente, na própria escola ou em outra escola do ensino regular, no turno inverso da escolarização.

A inclusão de pessoas com necessidades específicas se deu, inicialmente, com a criação das APAES (Associaçáo de Pais e Amigos dos Excepcionais), nos anos de 1950. De acordo com Hazard; Galváo Filho e Rezende (2007, p.19), "após muito tempo de rejeição e abandono, nos dois últimos séculos, as pessoas com necessidades passaram a ser objeto de políticas especiais". O histórico da vida escolar dessas pessoas remete ao tempo onde a atividade prevista era apenas o de receber alimento e abrigo. Somente mais tarde vieram a receber, nesses centros, um atendimento especializado voltado para a saúde, reabilitação, educação e trabalho. De acordo com COSTA et al.:

A primeira APAE criada no Brasil foi no Rio de Janeiro, em 1954 e em 1962 foi fundada a Federação Nacional das APAEs. No ano de 2001 estáo presentes em quase 2000 municípios brasileiros, dentre os seus principais programas de ação estão: a sensibilização, conscientização, prevenção, habilitação, reabilitação, inserção no mercado de trabalho e residência para as pessoas com deficiência em idade cronológica avançada. (COSTA et al., 2008, p. 1).

As APAES desempenham várias funções, tanto educativas como de atendimento à saúde. Podem ser classificadas quanto a sua função em dois tipos: APAEs escolas e APAEs clínicas. A APAE escola tem por finalidade atender o disposto na Constituição Federal e Estadual, na Lei de Diretrizes e Bases da Educação Nacional e no Estatuto da Criança e do Adolescente (ECA), buscando viabilizar mecanismos que irão garantir os direitos de cidadania das pessoas com deficiências especiais. 
A APAE clínica tem como objetivo oferecer atendimento especializado aos pacientes que apresentam diagnósticos de algumas deficiências, e os atendimentos especializados são nas áreas de fisioterapia, fonoaudiologia, educaçáo especial e psicologia.

A efetiva educação inclusiva vai além das açôes comunitárias, como as desenvolvidas nas APAEs, sendo preciso propiciar a ampliação do acesso destes alunos às classes comuns. Assim, aos professores que atuam no ensino regular, é necessário oportunizar um suporte técnico, a fim de estimular açôes igualitárias onde as crianças possam aprender juntas por meio de processos diferenciados e de formas criativas de atuação (TORRES, 2010, p.1).

É direito de todos os cidadãos terem uma educação de qualidade que os inclua no mundo, possibilitando a busca de seus objetivos e conhecimentos oferecendo os instrumentos necessários para que eles desenvolvam todas as suas potencialidades, seja no ambiente escolar, seja na vida diária, eliminando-se as barreiras que esses alunos têm para relacionar-se com o ambiente externo. (PONTES, 2008, p. 41).

Um fato que se pode ressaltar, no entanto, é que os professores não estão preparados para receber alunos com algum tipo de necessidade na sala de aula regular, mesmo tendo conhecimento de que é preciso saber trabalhar com a diversidade existente entre os educandos.

Com isso, o presente trabalho tem por objetivo reconhecer a realidade das pessoas com necessidades específicas, em especial nas APAEs de São Vicente do Sul e Jaguari/ RS , bem como ampliar os conhecimentos dos futuros profissionais do curso de licenciatura em Ciências Biológicas nessa área.

O trabalho buscou, também, avaliar a situação de atendimento das APAEs, interagir com alunos e profissionais, a fim de promover uma integração com o grupo PET- Biologia, conhecer a realidade das famílias dos alunos, bem como contribuir para a melhoria da qualidade de vida dos mesmos e verificar o interesse em realização de atividades do grupo PET-Biologia junto aos alunos com necessidades específicas.

\section{Material e métodos}

O trabalho foi realizado pelos alunos do Grupo PET-Biologia, do Curso de Licenciatura em Ciências Biológicas do Instituto Federal Farroupilha - Campus São Vicente do Sul/RS, nas APAEs de São Vicente do Sul e Jaguari/RS, no primeiro semestre de 2011.

Para esse trabalho, foi realizada uma pesquisa por meio de entrevista com os responsáveis pelas atividades desenvolvidas nas APAEs e com os pais dos alunos com necessidades específicas.

Após a realização das entrevistas, os dados foram analisados e discutidos com base na bibliografia. 
A APAE clínica de São Vicente do Sul conta com um técnico administrativo. Nela, os alunos possuem consultas marcadas semanalmente com atendimento nas terças e quintas-feiras. As mesmas têm transporte garantido pela prefeitura e frequentam os horários marcados para o atendimento. Na APAE de Jaguari, o atendimento é de clínica e escola. Os encontros são semanalmente e os alunos são separados por idade para a realização de atividades nas oficinas.

Através das entrevistas realizadas na APAE de São Vicente do Sul, observouse a necessidade de desenvolver atividades como artesanato, oficinas para confecção de brinquedos, pinturas e jogos educativos que ajudem os alunos a serem críticos e curiosos. Na APAE de Jaguari, foram desenvolvidas somente as atividades sugeridas pelo grupo diante a entrevista.

\section{Resultados e discussões}

Após a realização do levantamento de dados, observou-se que a APAE de São Vicente do Sul/RS (APAE -SVS) e APAE Jaguari/RS (APAE-J) são instituiçóes que prestam atendimentos clínicos e clínico/escolares, respectivamente. Os pacientes que frequentam as atividades seráo aqui chamados de alunos com algum tipo de necessidade específica.

Os resultados da entrevista, realizada com os funcionários das APAEs, encontram-se nas Figuras 1 e 2. Os resultados evidenciaram que a Figura 1(a) apresenta o grupo de funcionários que constituem o corpo administrativo da APAE-SVS e observou-se que $25 \%$ atuam como auxiliar administrativo, $50 \%$ prestam atendimento no setor de fonoaudiologia e $25 \%$ desenvolvem atividades de fisioterapia. Esses profissionais são contratados e trabalham no apoio dos alunos, por meio de consultas marcadas semanalmente, com atendimento nas terças e quintas-feiras. Para isso, a prefeitura municipal presta auxílio de transporte nos dias de atendimento.

Na Figura 1(b), está representado o grupo de funcionários que constituem o corpo administrativo da APAE - Jaguari/RS, sendo que 5\% atuam como psicólogos, 5\% como fonoaudiólogos, 5\% fisioterapeutas, 5\% pedagogos, 5\% assistentes sociais, $20 \%$ educadores especiais, $5 \%$ professores de educação física, $5 \%$ professores de dança, 5\% professores de artes e os $40 \%$ dos funcionários restantes se dividem na área administrativa e de serviços gerais. Os profissionais prestam serviço por meio de contrato e trabalham no apoio dos alunos atuando semanalmente, no atendimento escolar e clínico. 


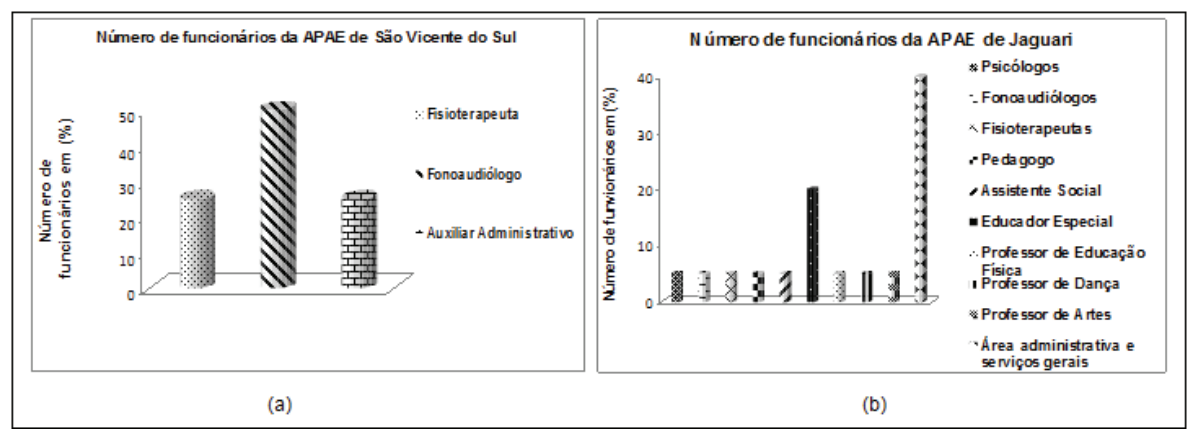

Figura 1: Número de funcionários da APAE: (a) São Vicente do Sul (b) Jaguari. Instituto Federal Farroupilha - Campus São Vicente do Sul/RS, 2011.

A Figura 2(a) apresenta os dados referentes às atividades de atendimento propostas na APAE - SVS e a porcentagem de alunos que frequentam cada uma. De acordo com os dados da pesquisa, o número total de pessoas com necessidades específicas, que frequentam a instituição, é de trinta e nove alunos. Destes, 52\% recebem atendimento nas atividades de informática, oferecidas como apoio ao desenvolvimento dos alunos, $25 \%$ fazem tratamento de fisioterapia e $23 \%$ de fonoaudiologia.

Na Figura 2(b) estáo os dados que apresentam as atividades desenvolvidas na APAE - Jaguari/RS. Nela, encontram-se quarenta e um alunos que realizam atividades escolares e recebem atendimento clínico. Por ser APAE escola, ela se divide em pré-alfabetização, com $12 \%$ de alunos, alfabetização, com $9 \%$, e educação infantil, também com 9\%. Observou-se, ainda, outras modalidades como: oficina I, com $21 \%$ de alunos, oficina II, com $21 \%$, oficina III, com $24 \%$ e oficina IV, com $14 \%$. Esses dados indicam a importância do acompanhamento de profissionais especializados para o apoio às atividades da APAE. Pois, conforme TORRES (2010), a inclusão é ainda considerada um desafio crescente, assim como o número de pessoas que necessitam de atendimento (IBGE, 2000

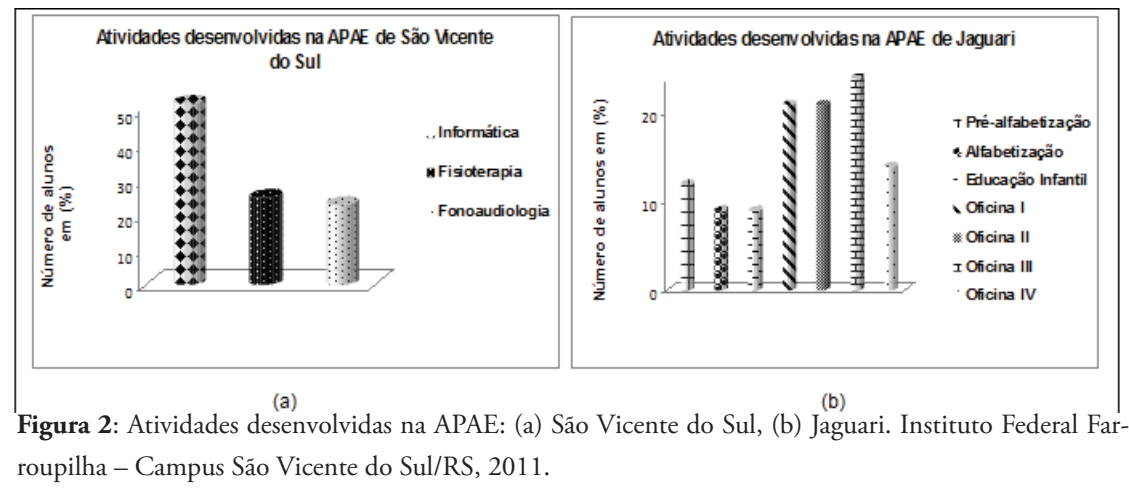

Nas Figuras 3 e 4, encontram-se os dados referentes à entrevista realizada com os pais dos alunos que frequentam a APAE - SVS e a APAE - Jaguari/RS. 
Os resultados da Figura 3(a) indicam as principais necessidades específicas encontrada na APAE-SVS. De acordo com os pais, são variadas as necessidades específicas dos filhos, incluindo Síndrome de Down, fenda lábio palatal, paralisia cerebral, hidrocefalia, deficiência intelectual e anoxia. Observou-se que a dificuldade intelectual prevalece nos alunos, estando presentes em 30\% dos frequentadores da APAE. As necessidades do tipo síndrome de Down, fenda lábio palatal, anoxia e deficiência intelectual, são frequentes em mais de um aluno.

As necessidades específicas, encontradas nos alunos da APAE de Jaguari/RS, estão na Figura 3(b), sendo que as principais são a deficiência intelectual, síndrome de Down, transtorno de desenvolvimento global, autismo e deficiência visual.

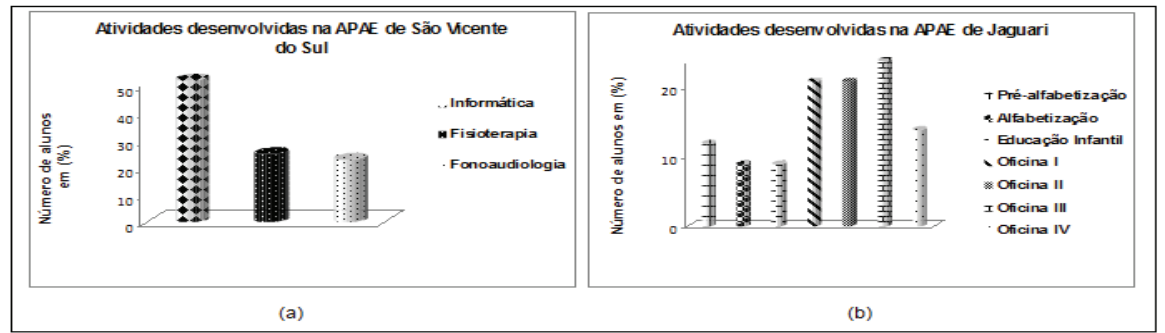

Figura 3: Deficiências encontradas nos alunos da APAE: (a) São Vicente do Sul; (b) Jaguari. Instituto Federal Farroupilha - Campus São Vicente do Sul/RS, 2011.

As Figuras 4(a) e 4(b) mostram os resultados referentes ao interesse dos pais em receberem apoio como forma de colaborar para a melhoria do atendimento dos alunos das APAEs.

De acordo com os pais entrevistados, em ambos os municípios, há interesse em açôes promovidas por acadêmicos das licenciaturas. Atividades lúdicas e de interação são levantadas como interessantes pelos pais.

Para os acadêmicos da licenciatura, esse é um momento de interagir e ampliar os conhecimentos sobre as necessidades específicas, pois, segundo Sborquia (2008, p.25), os professores necessitam incluir nas suas práticas não só conhecimentos específicos das disciplinas que lecionam, mas um conjunto de outras competências que concorrem para o sucesso na docência. A complexidade das açôes que envolvem a necessidade específica, de forma geral, justifica a necessidade do conhecimento sobre as mesmas e de projetos que contribuam para o aprimoramento dos acadêmicos de licenciatura como futuros profissionais da área de educação. 


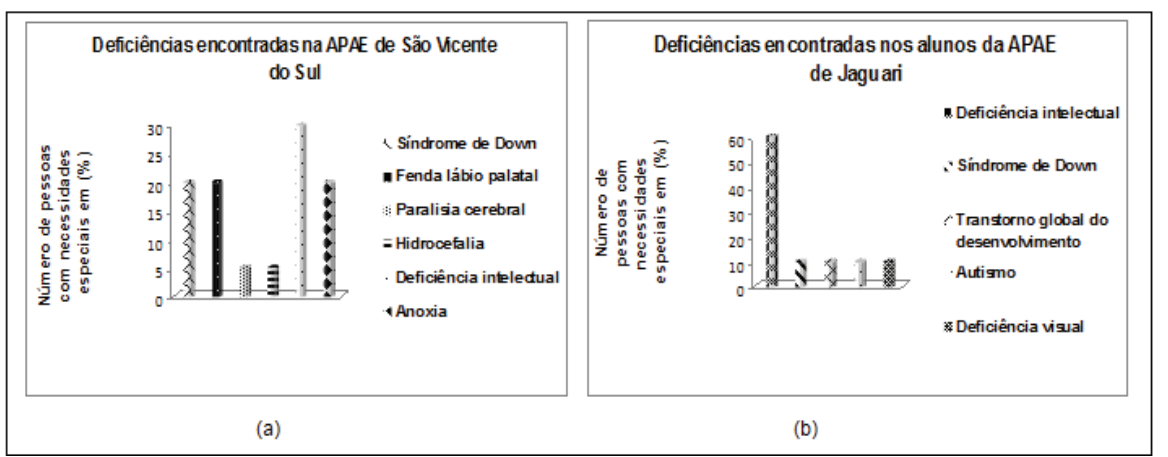

Figura 4: Sugestôes de atividades a serem desenvolvidas pelo grupo PET-Biologia nas APAEs: (a) de São Vicente do Sul; (b) Jaguari. Instituto Federal Farroupilha - Campus São Vicente do Sul/RS, 2011.

\section{Considerações finais}

O trabalho realizado pelas APAEs exerce um papel inicial e fundamental de inclusão social de pessoas com necessidades específicas, pelo qual, por meio de açóes de atendimento, consegue-se possibilitar a essas pessoas formas de convivência social e respeito pela diversidade. Porém, o que se busca é a complementação dessa etapa, por meio da inclusão dessas pessoas com algum tipo de necessidade específica em redes regulares de ensino.

Para que isso ocorra, se faz necessário que os professores tenham conhecimento e estejam aptos para atuarem, de forma eficiente, com alunos que apresentam necessidades educativas especiais. Dessa forma, é que o PET-Biologia do Curso de Licenciatura em Ciências Biológicas pretende dar seus primeiros passos, valorizando as APAEs e possibilitando experiências do grupo para a futura ação profissional, a fim de promover a inclusão das pessoas com necessidades específicas.

\section{Referências}

BRASIL. Senado Federal. Lei de Diretrizes e Bases da Educaçáo Nacional: no 9394/96. Brasília : 1996.

CONSELHO NACIONAL DE EDUCAÇÃO. Câmara de Educação Superior. Resoluçáo no 4/09, de 2 de outubro de 2009. Diário Oficial da União. Disponível em: <http://portal.mec.gov.br/dmdocuments/ rceb004_09.pdf>. Acesso em: jul. 2011.

COSTA, A. G. G. V. et al. A importância da equipe multidisciplinar na melhoria da qualidade de vida e inclusáo social de indivíduos portadores de necessidades especiais assistidos pela APAE de Viçosa, MG. Universidade Federal de Viçosa, MG. 2008, p. 1. Disponível em: <http://www.prac.ufpb.br/anais/Icbeu_anais/ anais/saude/multidisciplinar.pdf>. Acesso em: jul. 2011.

HAZARD, D.; GALVÃO FILHO, T.A.; REZENDE, A.L.A. Inclusáo digital e social de pessoas com deficiência: textos de referência para monitores de telecentros. Brasília: UNESCO, 2007, p. 19.

IBGE-Instituto Brasileiro de Geografia e Estatística. Censo demográfico, recenseamento geral do Brasil, 2000.

PLETSH, M.D. A formação de professores para a educação inclusiva: legislação, diretrizes políticas e resultados de pesquisas. Educar. Curitiba n. 33, 2009, p. 149.

PONTES, P. A. G. Criança e adolescente com deficiência: impossibilidade de opçáo pela sua educaçáo exclusivamente no atendimento educacional especializado. Inclusão - Revista de Educaçáo Especial, v. 4, n. 1, 2008, p. 41 . 
SBORQUIA, S. P. Da formaçáo e desenvolvimento profissional do professor da educaçáo física à inovaçáo educativa. Campinas, 2008, p. 25.

TORRES, R. Educação Especial e Inclusão. Revista Poli: saúde, educação e trabalho. Ano II, no 12, p. 4, jul./ ago., 2010.

\section{Correspondência}

Simone Medianeira Franzin - Instituto Federal Farroupilha de São Vicente do Sul. Rua 20 de Setembro, s/n, CEP 97420-000. São Vicente do Sul, Rio Grande do Sul, Brasil.

E-mail: simone.franzin@svs.iffarroupilha.edu.br - petbio.iffsvs@gmail.com - gabriela.bio2@gmail.com.

Recebido em 22 de julho de 2013

Aprovado em 20 de agosto de 2014 
